\title{
Article \\ Constant-Current and Constant-Voltage Output for Single-Switch WPT System with Composite Shielding Structure
}

\author{
Quanlei Zhang ${ }^{\mathbb{D}}$, Chunfang Wang *, Lingyun Yang and Zhihao Guo
}

School of Electrical Engineering, Qingdao University, Qingdao 266071, China; 2019026083@qdu.edu.cn (Q.Z.); qduyly@163.com (L.Y.); 17854291508@163.com (Z.G.)

* Correspondence: qduwcf@qdu.edu.cn

\begin{abstract}
With the development of wireless power transfer (WPT), the wireless charging has become a research hotspot. This paper proposes a novel single-switch hybrid compensation topology, which can change the compensation network to realize the constant-current (CC) and constant-voltage (CV) output. The zero voltage switching (ZVS) margin can be designed to increase the stability of the system. In addition, the magnetic coupler adopts a composite shielding structure composed of ferrite, nanocrystalline, and aluminium foil. The composite shielding structure has a better shielding effect on magnetic flux leakage, and its weight is lighter. The composite shielding structure is expected to be used in the wireless charging system of electric vehicles (EVs). Finally, an experimental prototype is built to verify the theoretical analysis, and the maximum efficiency can reach $91.4 \%$.
\end{abstract}

Keywords: wireless charging; soft-switching; constant-current; constant-voltage; electric vehicles

Citation: Zhang, Q.; Wang, C.;

Yang, L.; Guo, Z. Constant-Current and Constant-Voltage Output for Single-Switch WPT System with Composite Shielding Structure. World Electr. Veh. J. 2022, 13, 13. https:// doi.org/10.3390/wevj13010013

Academic Editor: Hiroshi Fujimoto

Received: 25 September 2021

Accepted: 13 December 2021

Published: 31 December 2021

Publisher's Note: MDPI stays neutral with regard to jurisdictional claims in published maps and institutional affiliations.

Copyright: (C) 2021 by the authors. Licensee MDPI, Basel, Switzerland. This article is an open access article distributed under the terms and conditions of the Creative Commons Attribution (CC BY) license (https:// creativecommons.org/licenses/by/ $4.0 /)$.

\section{Introduction}

With the development of wireless power transfer (WPT), some WPT products have gradually come into people's vision and received great attention. There are mainly two types of WPT systems: Near-field (non-radiative) and far-field (radiative) WPT systems [1,2]. The characteristic of far-field transmission is that the microwave radiation can exceed RF safety limits, making it less than ideal for applications. Near-field WPT can provide a high-efficiency system and has a stringent requirement on the RF limits. The near-field technique is more suitable for consumer electronic devices. The near-field WPT technology has the advantages of safety, reliability, and convenience [3,4], which can be used in different applications. For example, there are wireless charging solutions for electric vehicles (EVs) [5-7], drones [8,9], and implanted biomedical devices [10-12].

In the WPT system, the topologies are mainly divided into full-bridge inverters, halfbridge inverters, and single-switch inverters [13-15]. The topology of the single-switch circuit is shown in Figure 1. Compared with the full-bridge and half-bridge circuit [16-19], the single-switch circuit avoids the shoot-through of power switches in this topology, and the reliability of the WPT system is improved.

In addition, the battery charging generally adopts constant-current (CC) and constantvoltage (CV) charging $[20,21]$. In order to achieve the CC and CV output, three methods are used. The first method is to add the dc/dc converter behind the secondary-side rectifier, where the CC and CV output are controlled [22,23]. The second method is to change the switching frequency of MOSFETs in the inverter bridge. The authors in [24] proposed the double-sided LCC compensation network. The CV or CC output can be realized by changing the switching frequency without changing the circuit parameters. This topology is suitable for the wireless charging of batteries. In the single-switch circuit, the P-CLCL compensation network and frequency modulation control are used to achieve the high precision CC and CV output [25]. The third method is to control the working state of 
MOSFETs or relays. The switching of hybrid topologies was studied to achieve the CC and CV output [26-28]. In order to reduce the cost of the circuit and keep the resonant frequency unchanged, this paper proposes a method to realize the CC and CV output by switching the compensation network only at the secondary-side in the proposed topology, based on the single-switch circuit. In addition, with the increasing number of WPT products in the market, the problem of electromagnetic interference has gradually attracted the attention of users. In addition, this paper discussed the composite shielding structure, which is composed of ferrite, nanocrystalline, and aluminium foil.

The constant-current and constant-voltage charging curves of a lithium-ion battery are shown in Figure 2. Here, the $I_{\mathrm{CC}}$ is the charging current in CC mode, the $V_{\mathrm{CV}}$ is the charging voltage in CV mode, and the $I_{\min }$ is the cut-off charging current. Moreover, $I_{\mathrm{B}}$ is the variation trend of the battery current, and $V_{\mathrm{B}}$ is the variation trend of the battery voltage.

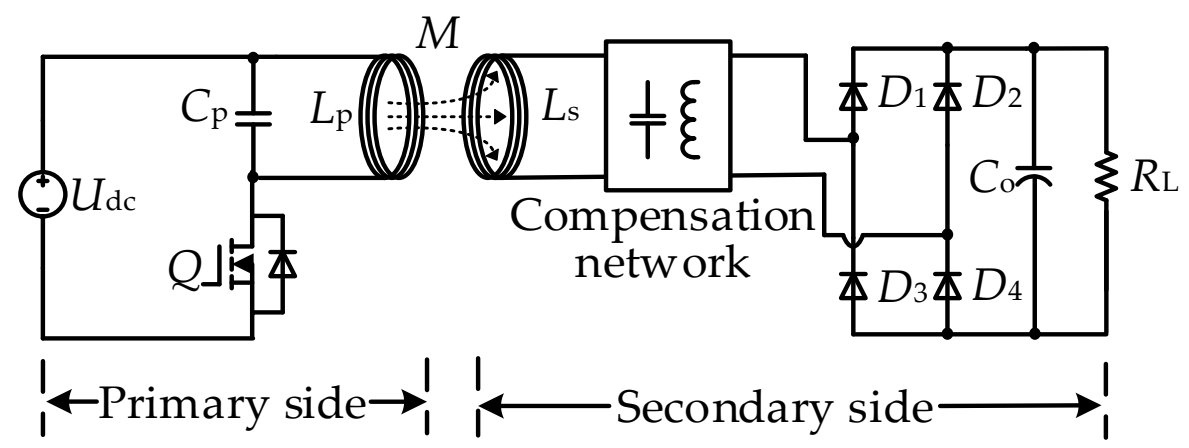

Figure 1. The topology of the single-switch circuit.

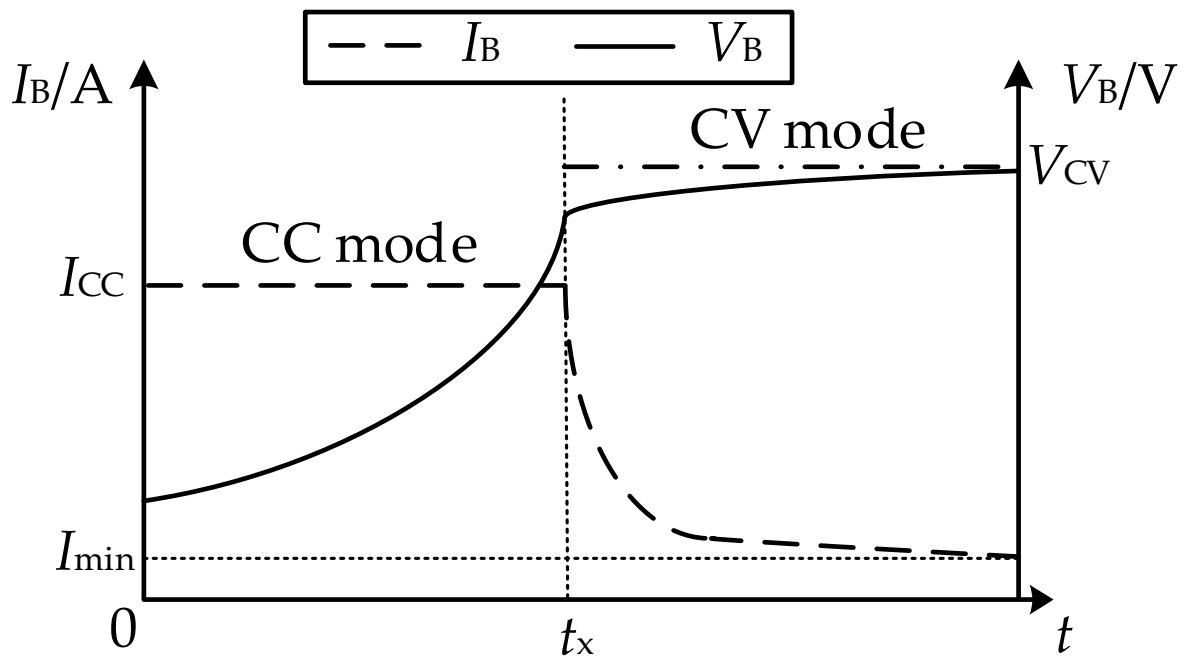

Figure 2. Constant-current and constant-voltage charging curves of a lithium-ion battery.

The rest of this article is organized as follows. A novel single-switch hybrid compensation topology is proposed, and the compensation networks of the CC and CV modes are analyzed in Section 2. In Section 3, the equivalent input AC voltage is calculated theoretically, then the zero voltage switching (ZVS) margin is designed, and thereafter, the $\mathrm{CC}$ and $\mathrm{CV}$ gain curves and the sensitivity of circuit parameters are analyzed. In Section 4, the magnetic coupler and circuit parameters are designed. An experimental prototype is built to verify the theoretical analysis in Section 5. The output current is $4 \mathrm{~A}$ in CC mode, and the output voltage is $48 \mathrm{~V}$ in CV mode. In addition, the output characteristics of constant-current and constant-voltage modes are analyzed, respectively. Finally, Section 6 concludes this article. 


\section{Analysis Compensation Network}

As shown in Figure $1, C_{\mathrm{p}}$ is the resonant capacitance at the primary-side. The primary side can be regarded as the $P$ compensation network, where $U_{\mathrm{dc}}$ is the input DC voltage, $Q$ is MOSFET, and $L_{\mathrm{p}}$ and $L_{\mathrm{S}}$ are the self-inductances of the transmitting coil and receiving coil, respectively. In addition, $M$ is the mutual inductance between the two coils, $D_{1}-D_{4}$ are four diodes to form the rectifier bridge, $C_{\mathrm{o}}$ is the output filter capacitor, and $R_{\mathrm{L}}$ is the DC output load. The secondary-side compensation network can be designed according to the requirements of the output.

When the compensation network of single-switch circuit is analyzed, Figure 1 can be simplified as Figure 3. Here, $\dot{U}_{\text {in }}$ is the equivalent AC voltage input to the compensation network, which is determined by the voltage waveform of $C_{\mathrm{p}}$. By applying Thévenin's and Norton's theorems, Figure 3a can be simplified as Figure $3 \mathrm{~b}$, and $L_{\mathrm{T}}=L_{\mathrm{s}}-M^{2} / L_{\mathrm{p}}$ is defined.

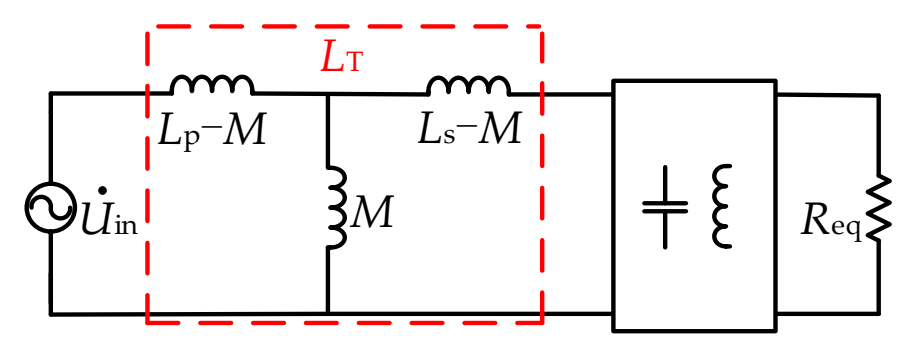

(a)

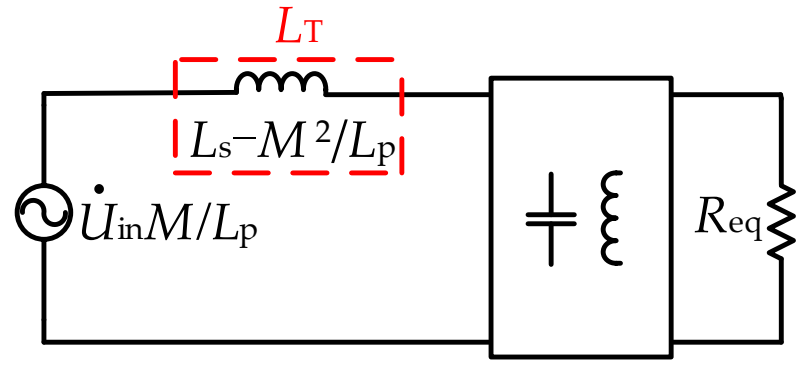

(b)

Figure 3. Analysis of equivalent circuit. (a) Equivalent circuit model; (b) simplified circuit model.

To realize the constant-current and constant-voltage output in the single-switch circuit, the hybrid P-LC and P-S compensation network can be designed as shown in Figure 4a. When $\mathrm{S}_{1}$ is connected to $C_{\mathrm{s} 1}$, the circuit can be regarded as the P-LC compensation with constant-current output characteristics. However, the design freedom of the loosely coupled transformer (LCT) is not high. When $\mathrm{S}_{2}$ is connected to $C_{\mathrm{s} 2}$, the circuit can be regarded as the P-S compensation with constant-voltage output characteristics. In order to improve the design freedom of the loosely coupled transformer, as shown in Figure $4 \mathrm{~b}$, the hybrid P-LCC and P-S compensation network is proposed. $C_{\mathrm{s} 1}$ and $C_{\mathrm{s} 2}$ can be used to adjust the output current in constant-current mode. The secondary side compensation network is changed by two switches $S_{1}$ and $S_{2}$. When both switches are turned on, the circuit is in constant-current mode, and the circuit can be regarded as the P-LCC compensation network. When both switches are turned off, and the circuit is in constant-voltage mode, the circuit can be regarded as the P-S compensation network.

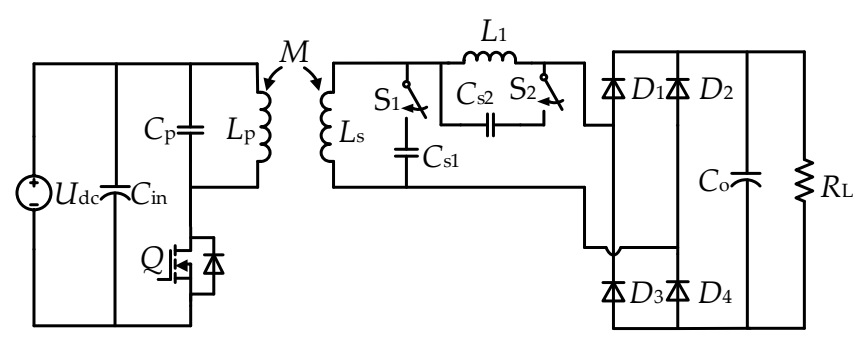

(a)

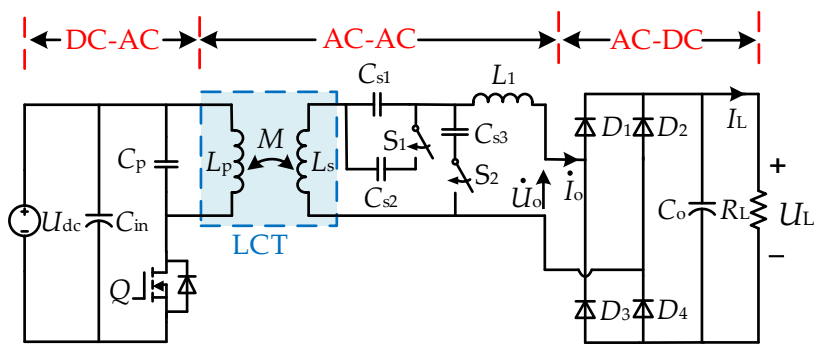

(b)

Figure 4. Hybrid topology of single-switch circuit. (a) The hybrid P-LC or P-S compensation network; (b) the proposed hybrid P-LCC or P-S compensation network. 
The equivalent circuit in constant-current mode is shown in Figure 5. Here, $\dot{I}_{\mathrm{o}}$ is the output current of the compensation network. As shown in Figure 5a, when switches $\mathrm{S}_{1}$ and $S_{2}$ are turned on, $C_{\mathrm{s} 1}$ and $C_{\mathrm{s} 2}$ are connected in parallel, and the equivalent capacitance is defined as $C_{\mathrm{T}}$. As shown in Figure $5 \mathrm{~b}, L_{\mathrm{T} 1}$ and capacitor $C_{\mathrm{T}}$ are inductive after they are connected in series, and the equivalent inductance is defined as $L_{\mathrm{T} 1}$. In order to achieve the constant-current output, the equivalent inductance $L_{\mathrm{T} 1}$ and $C_{\mathrm{s} 3}$ resonate at frequency $f$. In this case, Figure $5 \mathrm{~b}$ can be simplified as Figure $5 c$.

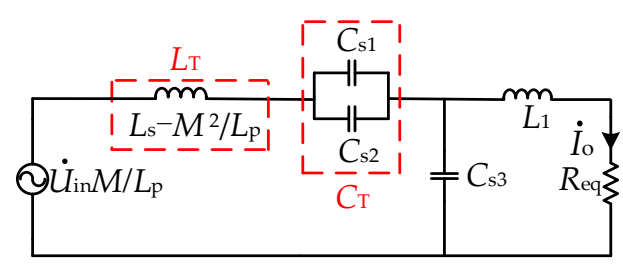

(a)

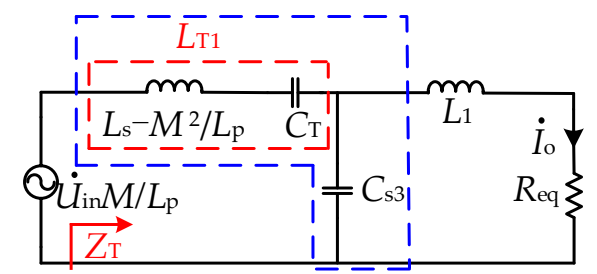

(b)

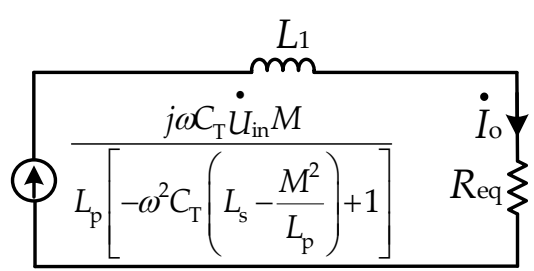

(c)

Figure 5. Equivalent model in CC mode. (a) Equivalent compensation network; (b) Simplified compensation network; (c) Equivalent current source model.

The equivalent model in constant-voltage mode is shown in Figure 6. Here, $\dot{U}_{\mathrm{o}}$ is the output voltage of the compensation network. In this mode, switches $S_{1}$ and $S_{2}$ are turned off, similarly, when the equivalent inductance $L_{\mathrm{T}}, L_{1}$, and $C_{\mathrm{s} 1}$ resonate at frequency $f$. In this case, Figure 6a can be simplified as Figure 6b.

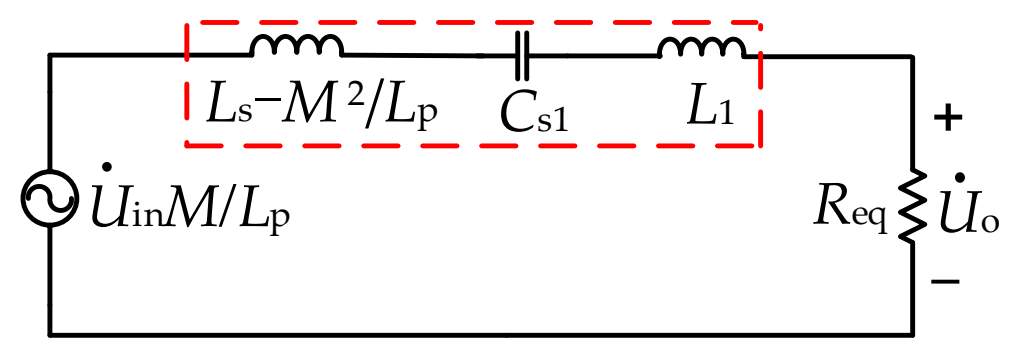

(a)

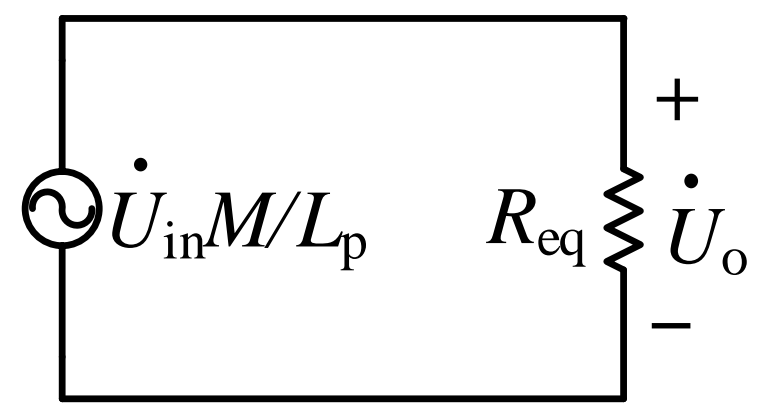

(b)

Figure 6. Equivalent model in CV mode. (a) Equivalent compensation network; (b) Equivalent voltage source model.

From Figure 5, the following conditions should be satisfied in CC mode.

$$
\left\{\begin{array}{l}
\frac{1}{j \omega C_{\mathrm{T}}}=\frac{1}{j \omega\left(C_{\mathrm{s} 1}+C_{\mathrm{s} 2}\right)} \\
j \omega L_{\mathrm{T} 1}=j \omega\left(L_{\mathrm{s}}-M^{2} / L_{\mathrm{p}}\right)+\frac{1}{j \omega C_{\mathrm{T}}} \\
\omega L_{\mathrm{T} 1}=\frac{1}{\omega C_{\mathrm{s} 3}}
\end{array}\right.
$$

where $\omega=2 \pi f, f=1 / T, f$ is the working frequency of the system, $T$ is the working period of the system. In constant-current mode, the output current can be expressed as:

$$
\dot{I}_{\mathrm{o}}=\frac{j \omega C_{\mathrm{T}} \dot{U}_{\mathrm{in}} M}{L_{\mathrm{p}}\left[-\omega^{2} C_{\mathrm{T}}\left(L_{\mathrm{s}}-\frac{M^{2}}{L_{\mathrm{p}}}\right)+1\right]}
$$

It can be obtained from (2) that the output current in CC mode is independent of $L_{1}$, and the value of $C_{\mathrm{T}}$ can be adjusted to change the output current. In order to make the 
input impedance $Z_{\mathrm{T}}$ resistive in Figure $5 \mathrm{~b}$, the relationship between $L_{1}$ and $C_{\mathrm{s} 3}$ can be expressed as:

$$
\omega L_{1}=\frac{1}{\omega C_{\mathrm{s} 3}}
$$

From Figure 6, the following condition should be satisfied in CV mode:

$$
\omega\left[L_{\mathrm{s}}-\left(M^{2} / L_{\mathrm{p}}\right)+L_{1}\right]=\frac{1}{\omega C_{\mathrm{s} 1}}
$$

The output voltage in CV mode can be expressed as:

$$
\dot{U}_{\mathrm{o}}=\frac{M \dot{U}_{\text {in }}}{L_{\mathrm{p}}}
$$

A full-bridge diode rectifier and capacitor filter are used to rectify the AC output current and filter the ripple voltage. The relationship between the output DC load current $I_{\mathrm{L}}$ and the peak AC current $i_{\mathrm{o}}$ before rectification is as follows:

$$
I_{\mathrm{L}}=\frac{2 i_{\mathrm{o}}}{\pi}=\frac{2 j \omega C_{\mathrm{T}} E_{1} M}{\pi L_{\mathrm{p}}\left[-\omega^{2} C_{\mathrm{T}}\left(L_{\mathrm{s}}-\frac{M^{2}}{L_{\mathrm{p}}}\right)+1\right]}
$$

where $E_{1}$ is the fundamental peak value of the equivalent input voltage source. The relationship between the output DC load voltage $V_{\mathrm{L}}$ and the peak AC voltage $v_{\mathrm{o}}$ before rectification is as follows:

$$
V_{\mathrm{L}}=\frac{\pi v_{\mathrm{o}}}{4}=\frac{\pi M E_{1}}{4 L_{\mathrm{p}}}
$$

The relationship between $R_{\mathrm{L}}$ and $R_{\mathrm{eq}}$ is as follows:

$$
R_{\mathrm{eq}}=\frac{8}{\pi^{2}} R_{\mathrm{L}}
$$

\section{Calculation of Equivalent Input AC Voltage Source}

For the single-switch circuit, the value of the $\mathrm{AC}$ voltage input to the compensation network is the voltage on the capacitor $C_{\mathrm{p}}$. However, the voltage waveform of $C_{\mathrm{p}}$ is not a complete square wave. Here, the voltage waveform of $C_{\mathrm{p}}$ is composed of a rectangular wave and half sine wave. It is necessary to calculate the equivalent $\mathrm{AC}$ voltage input to the compensation network. The relevant voltage and current waveforms are shown in Figure 7 . Here, $u_{\mathrm{gs}}$ is the driving signal of $Q, i_{\mathrm{Lp}}$ is the current of the transmitter, and $u_{\mathrm{Cp}}$ is the voltage of the capacitor $C_{\mathrm{p}}$. In addition, $u_{\mathrm{ds}}$ is the voltage stress on the switch $Q$. The voltage waveform of $C_{\mathrm{p}}$ in one operating period can be divided into three stages. During 0 to $t_{2}$, it is the conduction time of $Q$, and $u_{C p}$ is equal to the input DC voltage $U_{\mathrm{dc}}$. During $t_{2}$ to $t_{6}$, it is the blocking period of $Q$, and $u_{C p}$ is determined by the compensation network. As shown in Figure 8a, the waveform of $u_{C p}$ can be regarded as the sine wave. During $t_{6}$ to $t_{7}$, there is a current flowing through the anti-parallel diode of $Q$, which provides conditions for $Q$ to realize ZVS. Moreover, $u_{\mathrm{Cp}}$ is equal to the input DC voltage $U_{\mathrm{dc}}$, and the margin of ZVS is defined as $D_{1}$.

Since $C_{p}$ and the primary coil $L_{p}$ are in parallel, $u_{C p}=u_{L p}, u_{L p}$ is the voltage of the primary coil $L_{\mathrm{p}}$, and the average voltage of inductor is zero in one operating period. As shown in Figure 8 , it is the waveform of $u_{L p}$, where $E$ is the maximum resonant voltage of $C_{\mathrm{p}}$, and the expression of $u_{L \mathrm{p}}$ in one operating period can be written as follows:

$$
u_{\mathrm{Lp}}(t)= \begin{cases}U_{\mathrm{dc}} & \left(0<t \leq t_{2}\right) \\ U_{\mathrm{dc}}-\left(E+U_{\mathrm{dc}}\right) \sin \omega_{1}\left(t-t_{2}\right) & \left(t_{2}<t \leq t_{6}\right) \\ U_{\mathrm{dc}} & \left(t_{6}<t \leq t_{7}\right)\end{cases}
$$


where $\omega_{1}$ is the angular frequency of the sinusoidal half wave, and $\omega_{1}$ can be expressed as follows:

$$
\omega_{1}=\frac{\pi}{t_{6}-t_{2}}=\frac{\pi}{\left(1-D-D_{\mathrm{ZVS}}\right) T}
$$

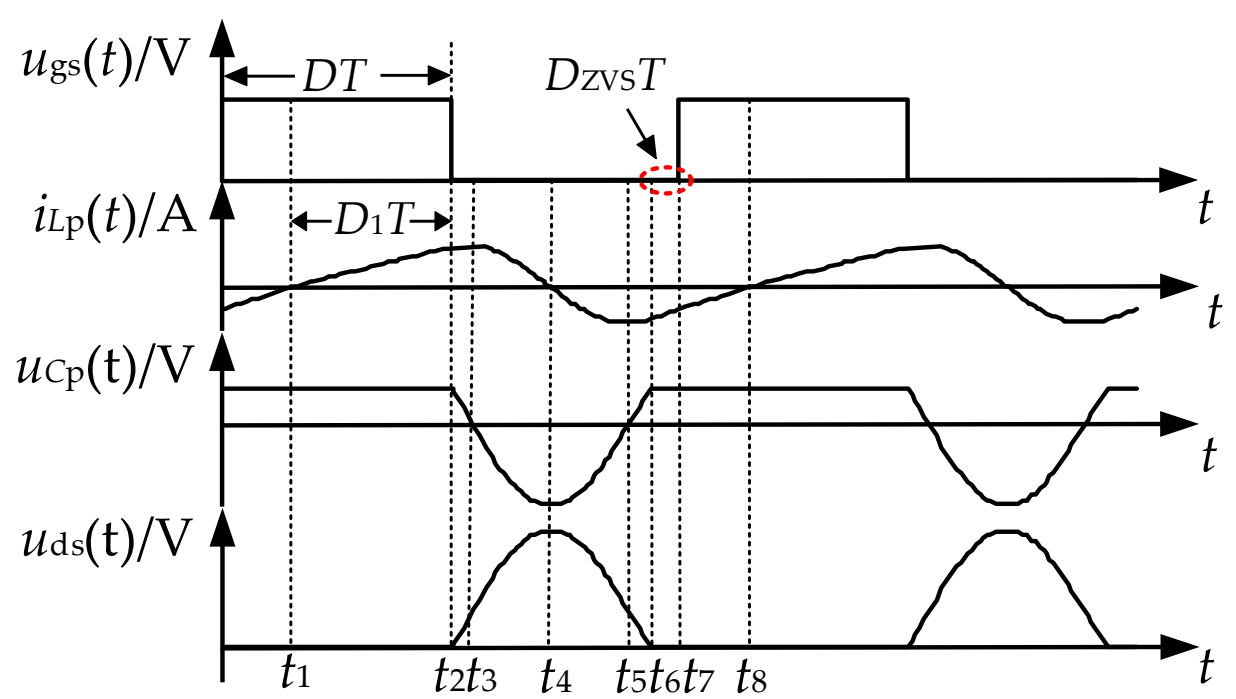

Figure 7. Relevant voltage and current operating waveforms.

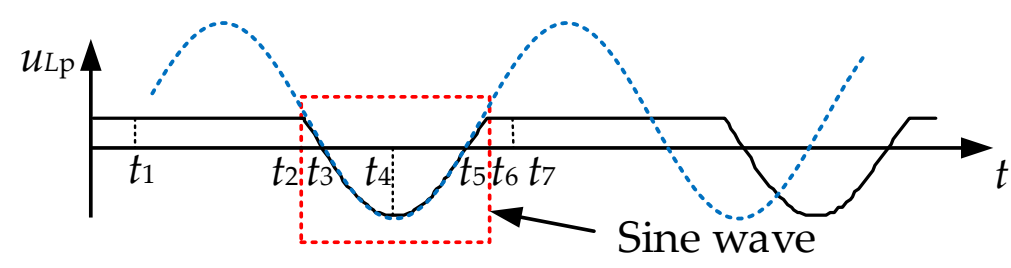

(a)

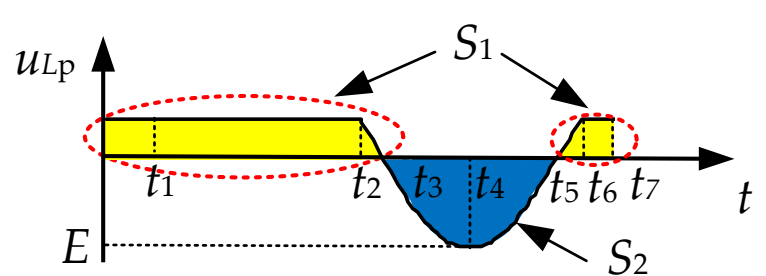

(b)

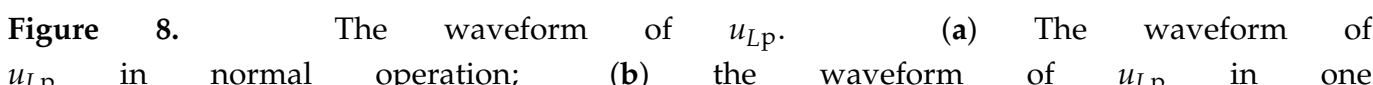
operating period.

Assuming $\Delta t=t_{3}-t_{2}=t_{6}-t_{5}, \Delta t$ can be expressed as follows:

$$
\Delta t=\frac{\pi \cdot \arcsin \left(\frac{U_{\mathrm{dc}}}{E+U_{\mathrm{dc}}}\right)}{180^{\circ} \cdot \omega_{1}}
$$

As shown in Figure $8 \mathrm{a}$, the symbols $t_{3}, t_{5}$, and $t_{6}$ can be expressed as follows:

$$
\left\{\begin{array}{l}
t_{3}=D T+\Delta t \\
t_{5}=\left(1-D_{\mathrm{ZVS}}\right) T-\Delta t \\
t_{6}=\left(1-D_{\mathrm{ZVS}}\right) T
\end{array}\right.
$$

As shown in Figure 8b, $S_{1}$ represents the yellow area, and $S_{2}$ represents the blue area, using the principle of volt-second balance, $S_{1}=S_{2}, S_{1}$ and $S_{2}$ can be expressed as follows:

$$
\left\{\begin{array}{l}
S_{1}=U_{\mathrm{dc}}\left(D+D_{\mathrm{ZVS}}\right) T+2 \int_{t_{2}}^{t_{2}+\Delta t} U_{\mathrm{dc}}-\left(E+U_{\mathrm{dc}}\right) \sin \omega_{1}\left(t-t_{2}\right) d t \\
S_{2}=\left|\int_{t_{2}+\Delta t}^{\left(1-D_{\mathrm{ZVS}}\right) T-\Delta t} U_{\mathrm{dc}}-\left(E+U_{\mathrm{dc}}\right) \sin \omega_{1}\left(t-t_{2}\right) d t\right|
\end{array}\right.
$$

In order to realize ZVS of $Q$ and improve the stability of the WPT system, setting the ZVS margin $D_{\mathrm{ZVS}}=5 \%$, the duty cycle $D$ is fixed at 0.5 . This paper sets the input DC 
voltage as $U_{\mathrm{dc}}=96 \mathrm{~V}, f=85 \mathrm{kHz}$. Through the Mathcad software, the intersection of $S_{1}$ and $S_{2}$ can be obtained using Formula (12). As shown in Figure 9, the intersection of $S_{1}$ and $S_{2}$ is $240 \mathrm{~V}$, in other words, $E=240 \mathrm{~V}$. The above analysis provides a theoretical basis for the value of $C_{\mathrm{p}}$. According to the value of $E$, the coefficients of $\Delta t, t_{3}$, and $t_{5}$ can also be obtained.

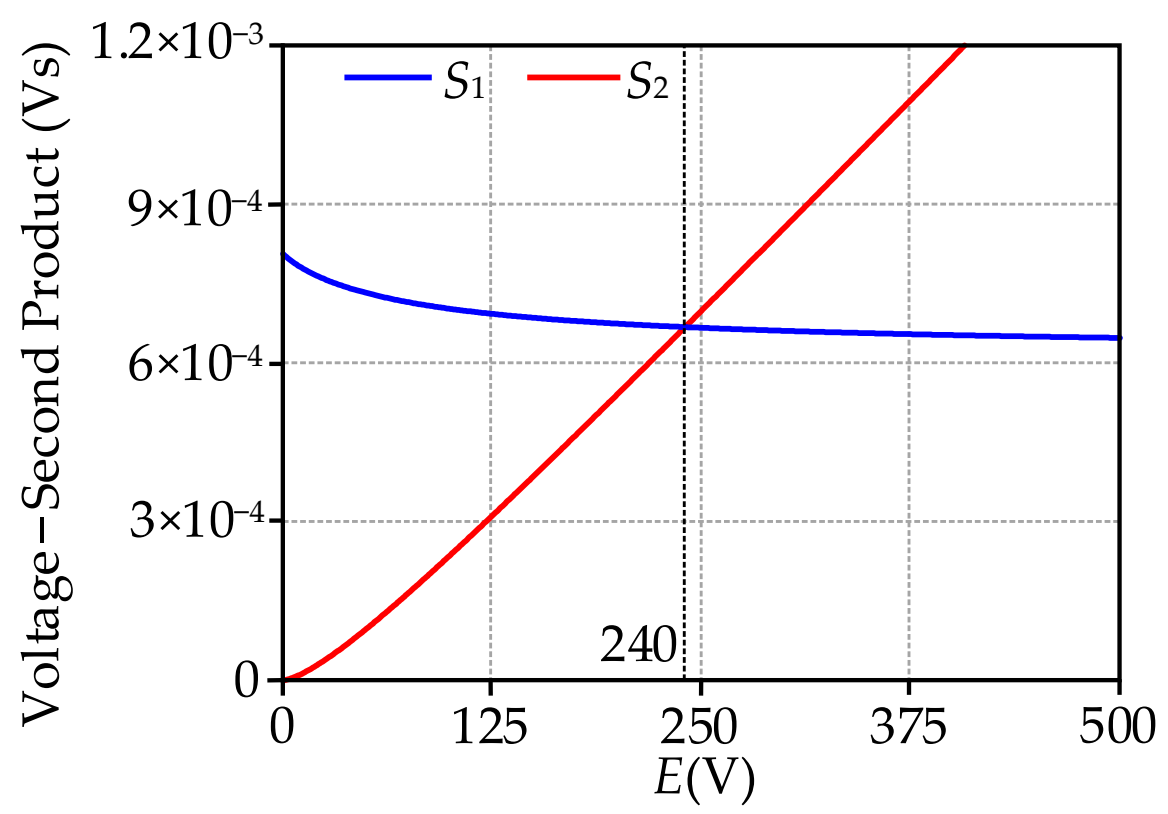

Figure 9. The curves of $S_{1}$ and $S_{2}$.

The peak voltage of $Q$ is the sum of the peak voltage of $C_{\mathrm{p}}$ and the input DC voltage $U_{\mathrm{dc}}, U_{Q \max }$ is the peak voltage of $Q$, which can be expressed as:

$$
U_{\mathrm{Qmax}}=E+U_{\mathrm{dc}}
$$

The waveform of $u_{L p}(t)$ can be decomposed by Fourier decomposition to obtain the fundamental amplitude. The expansion of Fourier series of $u_{L \mathrm{p}}(t)$ can be expressed as follows:

$$
\begin{aligned}
u_{L \mathrm{p}}(t) & =a_{0}+a_{1} \cos \omega t+b_{1} \sin \omega t+a_{2} \cos 2 \omega t+b_{1} \sin 2 \omega t+\ldots \\
& =a_{0}+\sum_{n=1}^{\infty}\left(a_{n} \cos n \omega t+b_{n} \sin n \omega t\right)
\end{aligned}
$$

where $a_{0}, a_{1}$, and $b_{1}$ can be expressed as:

$$
\begin{cases}a_{0}=\frac{1}{T} \int_{0}^{\left(D+D_{1}\right) T} U_{\mathrm{dc}} d t+\frac{1}{T} \int_{t_{2}}^{t_{6}} U_{\mathrm{dc}}-\left(E+U_{\mathrm{dc}}\right) \sin \omega_{1}\left(t-t_{2}\right) d t \\ a_{1}=\frac{2}{T} \int_{0}^{\left(D+D_{1}\right) T} U_{\mathrm{dc}} \cos \omega t d t+ \\ & \frac{2}{T} \int_{t_{2}}^{t_{6}} U_{\mathrm{dc}}-\left(E+U_{\mathrm{dc}}\right) \sin \omega_{1}\left(t-t_{2}\right) \cos \omega t d t \\ b_{1}=\frac{2}{T} \int_{0}^{\left(D+D_{1}\right) T} U_{\mathrm{dc}} \sin \omega t d t+ & \frac{2}{T} \int_{t_{2}}^{t_{6}} U_{\mathrm{dc}}-\left(E+U_{\mathrm{dc}}\right) \sin \omega_{1}\left(t-t_{2}\right) \sin \omega t d t\end{cases}
$$

The expansion of Fourier series of $u_{L p}(t)$ can also be expressed as:

$$
u_{L \mathrm{p}}(t)=E_{0}+E_{1} \cos (\omega t+\varphi)+\sum_{n=2}^{\infty} E_{n} \cos \left(n \omega t+\varphi_{n}\right)
$$

where $E_{0}=a_{0}, E_{1}=\sqrt{a_{1}^{2}+b_{1}^{2}}, \varphi=\arctan \left(-b_{1} / a_{1}\right) . E_{1}$ represents the fundamental amplitude, and $E_{0}$ represents the DC component. 
For the single-switch circuit, when the duty cycle $D$ is fixed, the values of $C_{p}$ are mainly used to adjust the ZVS margin. From Figure 7, when the driving signal of $Q$ turns off at $t_{2}$, the $C_{\mathrm{p}}, L_{\mathrm{e}}$, and $R_{\mathrm{e}}$ will have a zero input response, and the range values of $C_{\mathrm{p}}$ can be determined from the perspective of energy attenuation. The simplified circuit model is shown in Figure 10. Here, the reflected impedances from the secondary to the primary can be expressed as $Z_{\mathrm{T}}, Z_{\mathrm{T}}=j \omega L_{\mathrm{e}}+R_{\mathrm{e}}$.

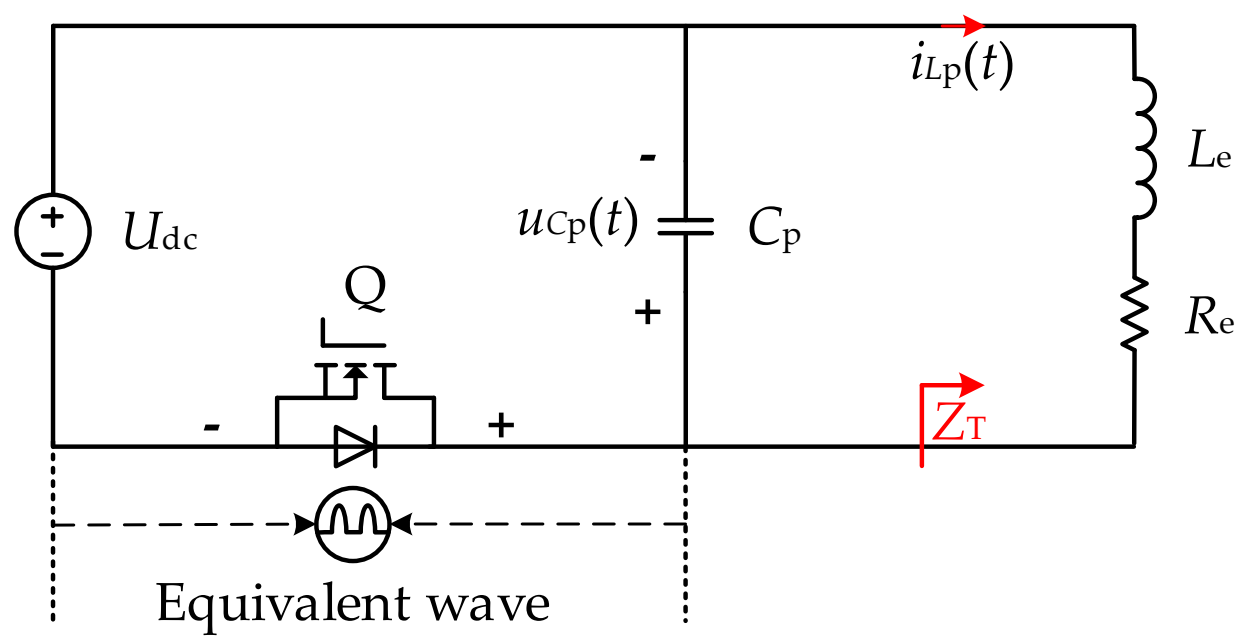

Figure 10. The simplified circuit model.

From Figure 10, it can be seen that $i_{L \mathrm{p}}\left(t_{1}\right)=0$, and the charging time of $L_{\mathrm{p}}$ is equal to $D_{1} T$. It should be noted that $D_{1} \leq D \cdot i_{L \mathrm{p}}(t)$ can be expressed as:

$$
i_{\mathrm{Lp}}(t)=\frac{U_{\mathrm{dc}}}{R_{\mathrm{e}}}\left(1-e^{\frac{-R_{\mathrm{e}}}{\mathrm{Le}_{\mathrm{e}}}\left(t-t_{1}\right)}\right)\left(t_{1} \leq t \leq t_{2}\right)
$$

At time $t_{2}$, the total energy stored by $L_{\mathrm{p}}$ and $C_{\mathrm{p}}$ can be expressed as:

$$
W=\frac{1}{2} L_{\mathrm{p}} i_{L \mathrm{p}}\left(t_{2}\right)^{2}+\frac{1}{2} C_{\mathrm{p}} U_{\mathrm{dc}}^{2}
$$

At time $t_{4}, i_{L p}=0$, the voltage value of $C_{\mathrm{p}}$ rises to the maximum. The rate of energy attenuation is $e^{\frac{-R_{\mathrm{e}}}{L_{\mathrm{e}}}}$, the time of energy attenuation is $\left(\frac{1-D-D_{\mathrm{ZVS}}}{2}\right) T$.

$$
e^{\frac{-R_{\mathrm{e}}}{L_{\mathrm{e}}}\left(\frac{1-D-D_{\mathrm{ZVS}}}{2}\right) T} W=\frac{1}{2} C_{\mathrm{p}} E^{2}
$$

\section{Simulation Verification}

The waveforms of $u_{\mathrm{ds}}$ and $u_{C p}$ versus $C_{\mathrm{p}}$ values in Saber simulation are shown in Figure 11. It can be seen that with the increasing value of $C_{\mathrm{p}}$, the maximum value of $u_{\mathrm{ds}}$ decreases gradually, and the ZVS margin $D_{\text {ZVS }}$ decreases until it disappears.

The theoretical calculation in Section 3 provides the basis for the actual value of $C_{\mathrm{p}}$. When the input DC voltage is $96 \mathrm{~V}$ and the switching frequency $f$ is $85 \mathrm{kHz}$, in order to obtain a $5 \%$ ZVS margin, the peak voltage of $C_{\mathrm{p}}$ should be about $240 \mathrm{~V}$. As shown in Figure 11b, when other circuit parameters are determined, the value of $C_{\mathrm{p}}$ is changed continuously in Saber simulation until the value of $u_{C p}$ is about $240 \mathrm{~V}$, and $C_{\mathrm{p}}=64.5 \mathrm{nF}$. When $C_{\mathrm{p}}=64.5 \mathrm{nF}$, the ZVS margin measured in the simulation is about $5.5 \%$, which is close to the design target of $5 \%$, indicating that the calculation method is reliable in Section 3. 
As shown in Figure 12, the fundamental amplitude after Fourier decomposition is 156.25 V, when $C_{\mathrm{P}}$ is set as $64.5 \mathrm{nF}$ in Saber simulation. The fundamental amplitude after Fourier decomposition is $158.3 \mathrm{~V}$ by (17). The values of the calculation and the simulation results can match well, and thus, validate the correctness of the theoretical analysis in Section 3.

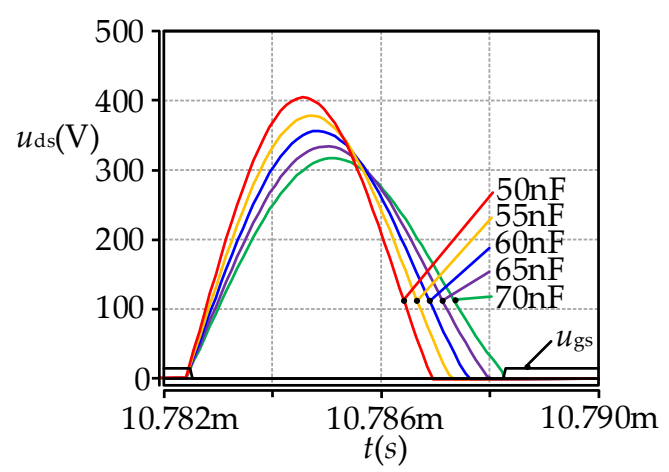

(a)

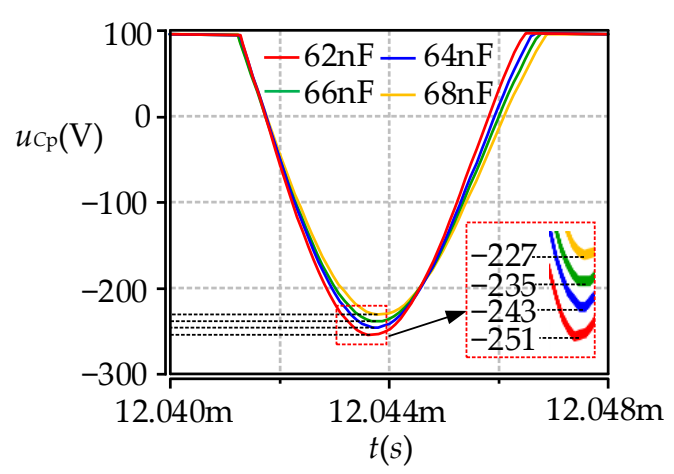

(b)

Figure 11. The waveforms of $u_{\mathrm{ds}}$ and $u_{\mathrm{Cp}}$ versus $C_{\mathrm{p}}$ values in Saber simulation. (a) The waveforms of $u_{\mathrm{ds}}$ versus $C_{\mathrm{p}}$ values; (b) the waveforms of $u_{C p}$ versus $C_{\mathrm{p}}$ values.

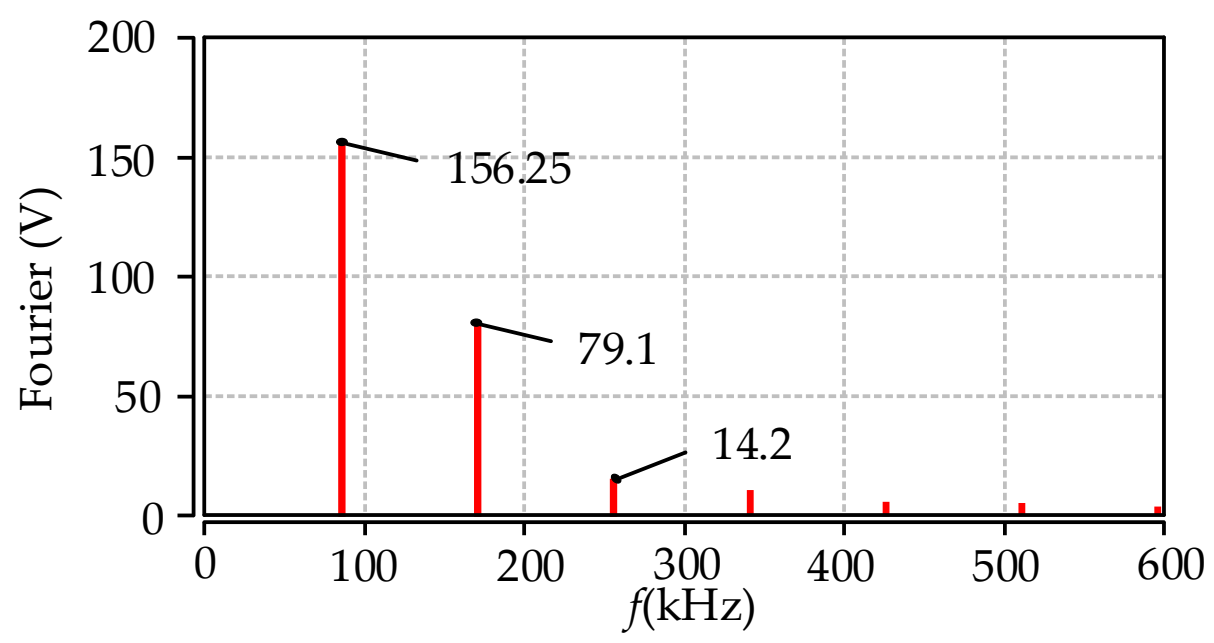

Figure 12. Fourier decomposition diagram of the voltage $u_{C p}$ in Saber simulation.

When all the circuit parameters are determined, the gain curve in the constant-current and constant-voltage modes can be drawn. As shown in Figure 13, it is the current gain curve in constant-current mode and the voltage gain curve in constant-voltage mode. In addition, it can be seen that the current gain value $G_{i}(f)$ at $85 \mathrm{kHz}$ is 0.042 , and the voltage gain value $G_{v}(f)$ at $85 \mathrm{kHz}$ is 0.50 . This indicates that when the input DC voltage is $96 \mathrm{~V}$ and the driving frequency is $85 \mathrm{kHz}$, the output current is about $4 \mathrm{~A}$, and the output voltage is approximately $48 \mathrm{~V}$.

In order to analyze the influence of the components on the output current and voltage, the sensitivity of the circuit parameters is analyzed. As shown in Figure 14, it is the normalized output with varying normalized parameters. In addition, it can be seen from Figure 14a that $L_{1}$ has no effect on the output current in constant-current mode, and the values of $C_{\mathrm{T}}$ and $C_{\mathrm{s} 3}$ can be used to adjust the output current. Therefore, the design freedom of the loosely coupled transformer is improved. 


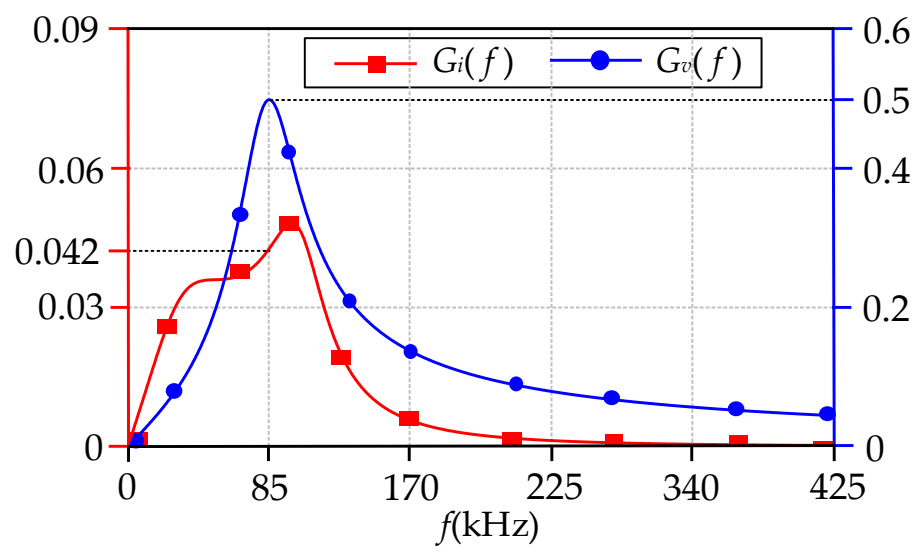

Figure 13. The curves of $G_{v}(f)$ and $G_{i}(f)$ versus driving frequency.

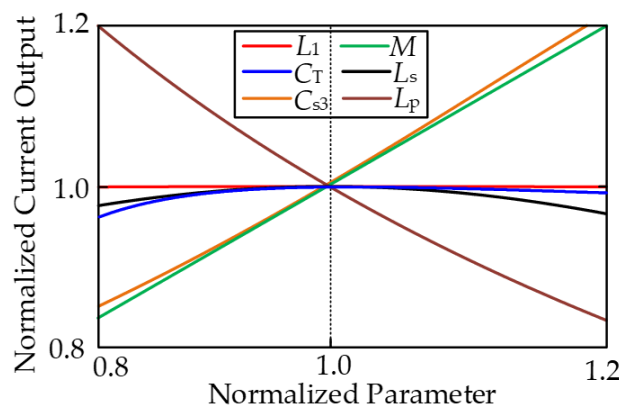

(a)

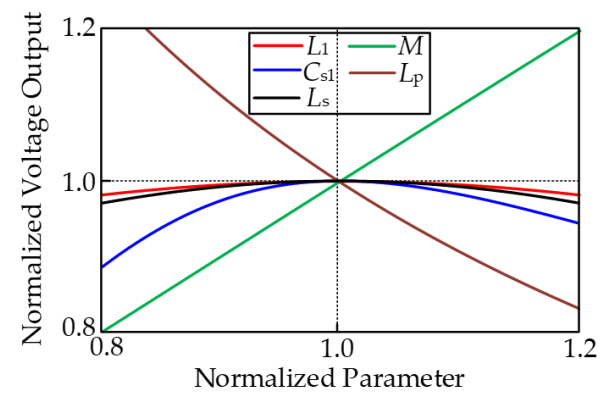

(b)

Figure 14. Normalized output with varying normalized parameters. (a) The curves in CC mode; (b) the curves in CV mode.

It can be seen from Figure $14 \mathrm{~b}$ that the variations of $L_{1}$ are not sensitive to the output voltage in constant-voltage mode.

As shown in Figure 15, it is the composite shielding structure of magnetic coupler. The first layer of the shielding structure on the receiving coil side of the magnetic coupler is ferrite, the second layer is nanocrystalline strip, and the third layer is aluminium foil. As shown in Figure 16, it is the cross-sectional magnetic flux density cloud images of different shielding structures.

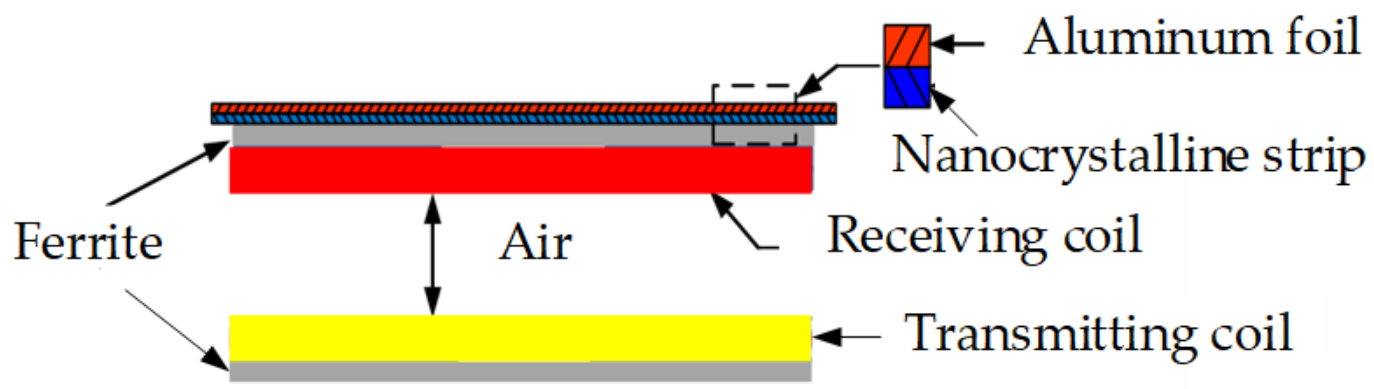

Figure 15. Composite shielding structure of magnetic coupler.

The traditional shielding layer structure can be divided into two types, one is a singlelayer shielding structure composed of ferrite, the other is a double-layer shielding structure composed of ferrite and aluminium plate. Compared with the double-layer shielding structure, the magnetic flux density in the air of single-layer shielding structure is higher. The double-layer shielding structure effectively reduces the magnetic field distribution in the non-working area, but the magnetic field in the working area is also reduced. The thickness of the iron-based nanocrystalline strip is $26 \mu \mathrm{m}$, the resistivity is $137 \mu \Omega \cdot \mathrm{cm}$, and the saturation magnetic induction is as high as $1.6 \mathrm{~T}$. 


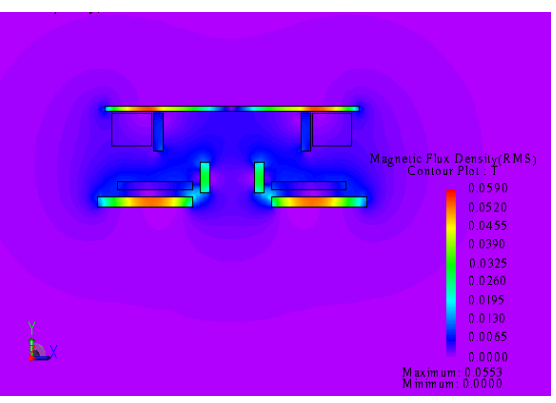

(a)

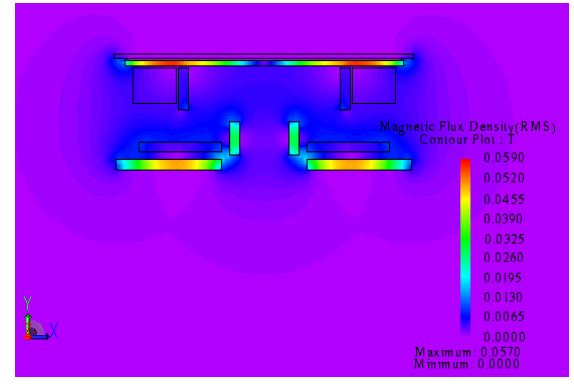

(b)

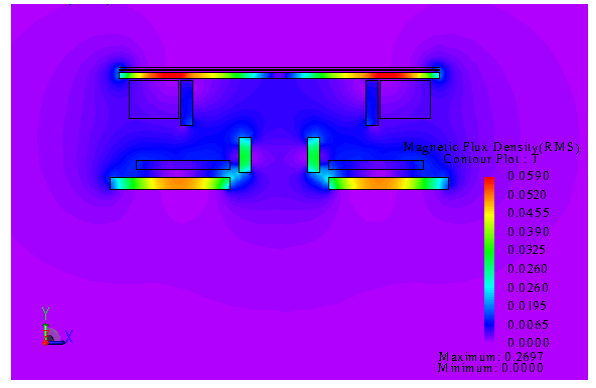

(c)

Figure 16. Cross-sectional magnetic flux density cloud images of different shielding structures. (a) Single-layer shielding structure; (b) double-layer shielding structure; (c) composite shielding structure.

In the composite shielding structure, the magnetic field in the non-working area above the receiving coil decreases and the magnetic field in the working area increases. For the double-layer shielding structure, the shielding effect at $240 \mathrm{~mm}$ outside of the magnetic coupler is increased by $14.85 \%$, and the coupling coefficient is increased by $28.64 \%$. When the composite shielding structure is adopted, the shielding effect at $240 \mathrm{~mm}$ outside of the magnetic coupler is increased by $20.32 \%$, and the coupling coefficient is increased by $37.86 \%$. The parameters of different types of shielding structures for receiving coil, are shown in Table 1. Moreover, the flow chart of parameter design is shown in Figure 17. As long as the values of self-inductance and mutual inductance are determined in the singleswitch WPT system, the compensation network parameters can be designed according to the flow chart, and the method is universal.

Table 1. Parameters of different types of shielding structures for receiving coil.

\begin{tabular}{ccc}
\hline Magnetic Coupler & Parameter & Value \\
\hline single shield magnetic coupler & Thickness of ferrite & $2.5 \mathrm{~mm}$ \\
\hline \multirow{2}{*}{ double shield magnetic coupler } & Thickness of ferrite & $2.5 \mathrm{~mm}$ \\
& Thickness of aluminium plate & $2 \mathrm{~mm}$ \\
\hline \multirow{3}{*}{ composite shield magnetic coupler } & Thickness of ferrite & $1 \mathrm{~mm}$ \\
& Thickness of aluminium foil & $0.1 \mathrm{~mm}$ \\
& Thickness of nanocrystalline strips & $26 \mu \mathrm{m}$ \\
\hline
\end{tabular}

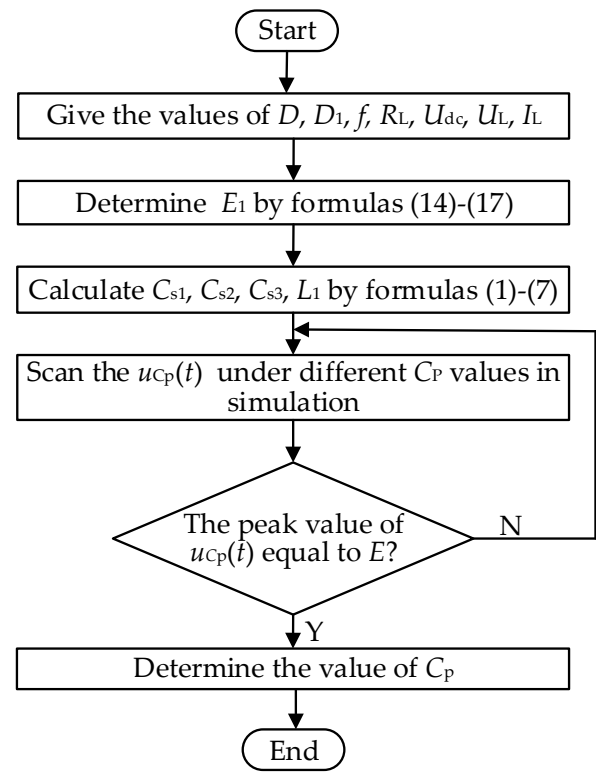

Figure 17. Flow chart of parameter design. 


\section{Experimental Verification}

The experimental platform is built through the experimental parameters in Table 2, due to the variation of self-inductance and mutual inductance in different shielding structures. The values of compensation capacitances should be different, and the compensation network parameters given in Table 2 are only designed on the basis of composite shielding structure. Here, it should be explained that the rated power experiment is only conducted in the composite shielding structure. Due to the changes of self-inductance and mutual inductance under other shielding structures, the output power will also change.

As shown in Figure 18, the experimental platform mainly includes the primary circuit, secondary circuit, magnetic coupler, oscilloscope, and electronic load. The theoretical analysis can be verified through the experimental platform. Q is SiC MOSFET (CGE1M120080), and the secondary rectifier diodes are DPG30C $300 \mathrm{HB}$. The system is powered by a dc voltage source. Metallized polypropylene film capacitors (CBB) are used as compensation components. The STM32F103 is used to generate switching signals for the inverter. The transmitters and the receiver were wound using Litz wires. The mutual inductance and self-inductance were measured by the Agilent 4263B LCR meter. The rocker switches $S_{1}$ and $S_{2}$ are used to switch the compensation networks to achieve the constant-current output or constant-voltage output.

Due to the limitation of the experimental conditions, the battery is replaced by the electronic load as the load. The electronic load (IT8616) can be used to change the resistance load to verify the output characteristics of the proposed topology.

Table 2. Experimental parameters.

\begin{tabular}{ccc}
\hline Symbol & Definition & Value \\
\hline$U_{\mathrm{dc}}$ & Input DC voltage & $96 \mathrm{~V}$ \\
$C_{\mathrm{p}}$ & Resonant capacitance at the primary-side & $64.5 \mathrm{nF}$ \\
$L_{\mathrm{p}}$ & Inductance of the transmitter coil & $29.6 \mu \mathrm{H}$ \\
$L_{\mathrm{s}}$ & Inductance of the receiving coil & $29.6 \mu \mathrm{H}$ \\
$M$ & Mutual inductance between $L_{\mathrm{p}}$ and $L_{\mathrm{s}}$ & $11.53 \mu \mathrm{H}$ \\
$C_{\mathrm{s} 1}$ & Resonant capacitance at the secondary-side & $86.6 \mathrm{nF}$ \\
$C_{\mathrm{s} 2}$ & Resonant capacitance at the secondary-side & $363.4 \mathrm{nF}$ \\
$C_{\mathrm{s} 3}$ & Resonant capacitance at the secondary-side & $202.4 \mathrm{nF}$ \\
$L_{1}$ & Resonant inductance at the secondary-side & $17.3 \mu \mathrm{H}$ \\
$f$ & Operating frequency & $85 \mathrm{kHz}$ \\
$D$ & Duty cycle & 0.5 \\
$D_{\mathrm{ZVS}}$ & ZVS margin & 0.05 \\
\hline
\end{tabular}

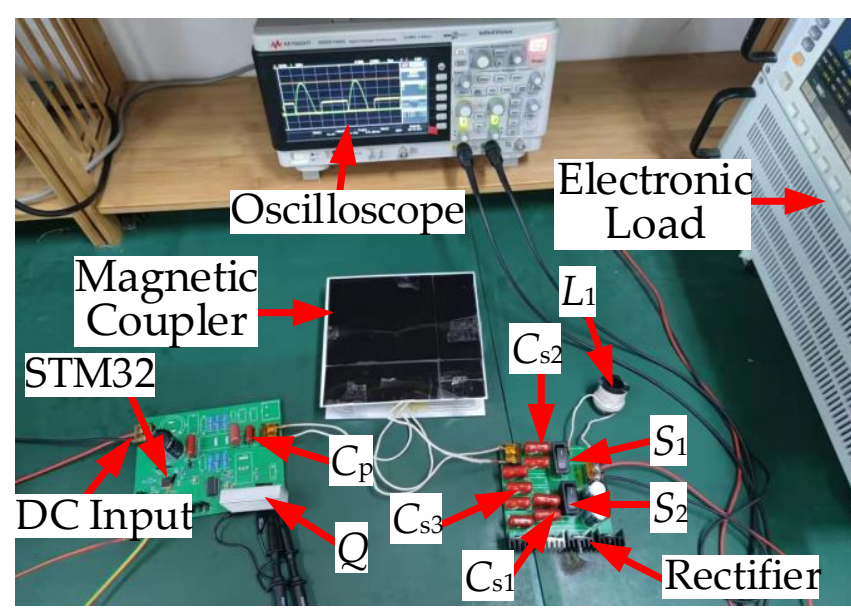

Figure 18. Exterior appearance of the proposed WPT prototype. 
The control flowchart of the proposed WPT system for the CC and CV modes is shown in Figure 19. Here, $u_{\text {ref }}$ is the critical reference voltage at the conversion point between the CC and CV modes and $I_{\min }$ is the lower limit of the output current. When the sampling voltage $u_{\mathrm{o}}$ is lower than the reference value $u_{\text {ref }}$, the switching signals are generated to drive the MOSFET $(\mathrm{Q})$, and the system is then in the CC mode.

When the sampling value $u_{\mathrm{o}}$ is higher than or equal to the reference value $u_{\text {ref }}$, the CV mode is selected. With the load $R_{\mathrm{L}}$ increasing in CV mode, the output current decreases gradually. Considering the possible problems (high current or high voltage spikes) caused by the transition point, a switching method is proposed here to avoid the problems. A short period of time before and after the mode convention point, the PWM signal of Q is closed. Although it causes a short charging pause, for a few hours of the real charging process, this effect can be ignored.

In the experiments, the variation of the load resistance is 6-12 $\Omega$ in constant-current mode, and the variation of the load resistance is $12-24 \Omega$ in constant-voltage mode. In order to verify that ZVS can be realized in the experiments, the ZVS waveforms were measured under the minimum and maximum load conditions. From Figure 20, the ZVS margin is $6.2 \%$ when $R_{\mathrm{L}}$ is set as $6 \Omega$, and the ZVS margin is $4.76 \%$ when $R_{\mathrm{L}}$ is set as $24 \Omega$. The design of ZVS margin ensures the ZVS of switch $Q$.

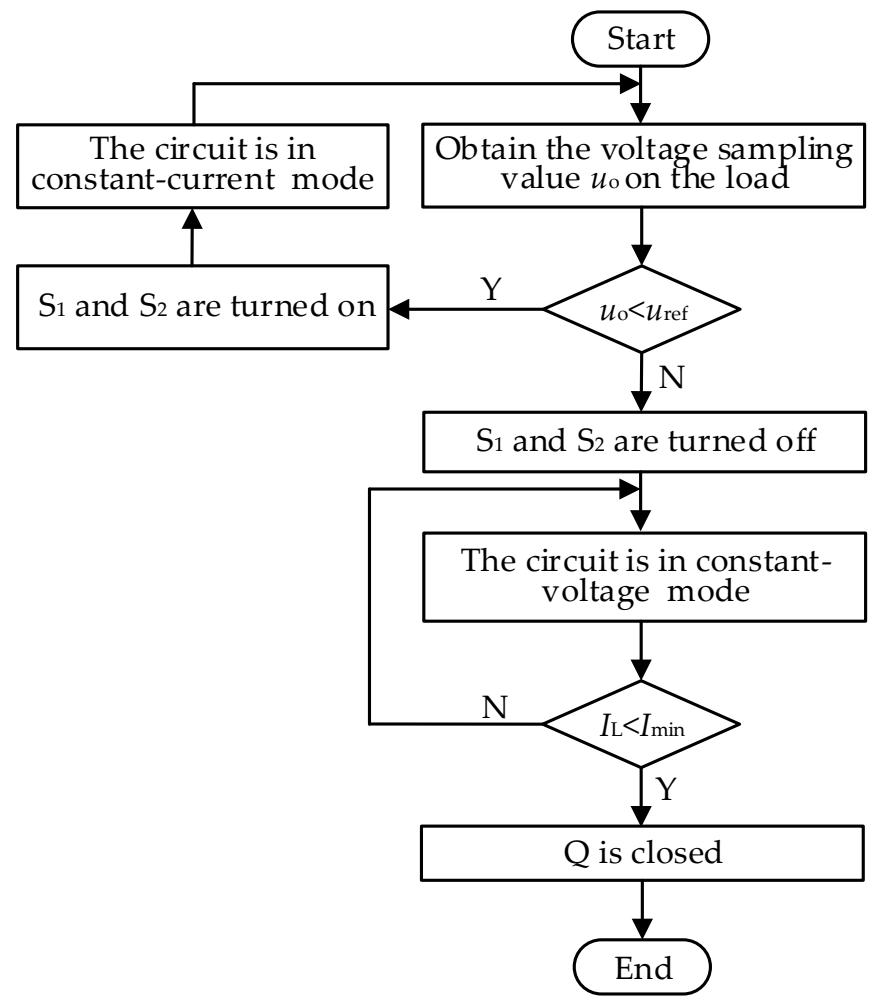

Figure 19. Control flowchart of the proposed WPT system for the CC and CV modes.

As shown in Figure 21, the performance of the proposed WPT system is tested when the load is suddenly changed. In Figure 21a,b, it can be found that the proposed WPT system can maintain a constant output current in the CC mode and a constant output voltage in the $C V$ mode. Figure 22 gives the measured output currents and voltages versus the load. As shown in Figure 23, the maximum efficiency is $91.4 \%$ in CC mode, and the maximum efficiency is $90.2 \%$ in CV mode. As the current flowing through the coils increases when switching from the CC mode to the CV mode, the loss increases. Therefore, the efficiency sags at the mode transition. 


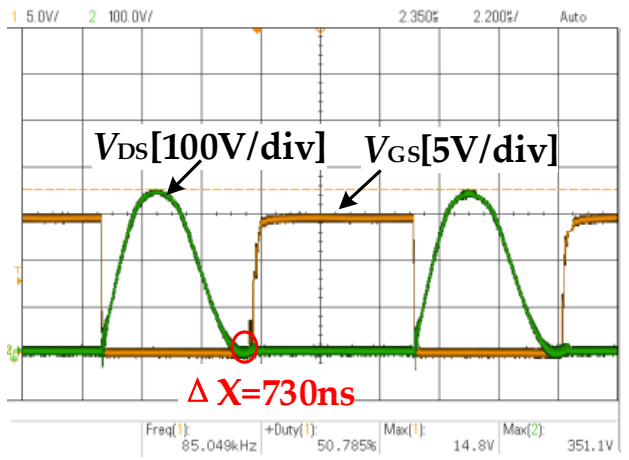

(a)

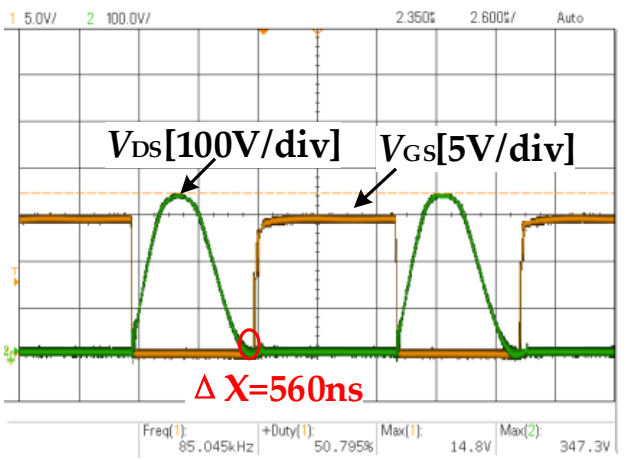

(b)

Figure 20. ZVS waveforms under the minimum and maximum load conditions. (a) ZVS waveform of $\mathrm{Q}$ when $R_{\mathrm{L}}=6 \Omega$; (b) ZVS waveform of $\mathrm{Q}$ when $R_{\mathrm{L}}=24 \Omega$.

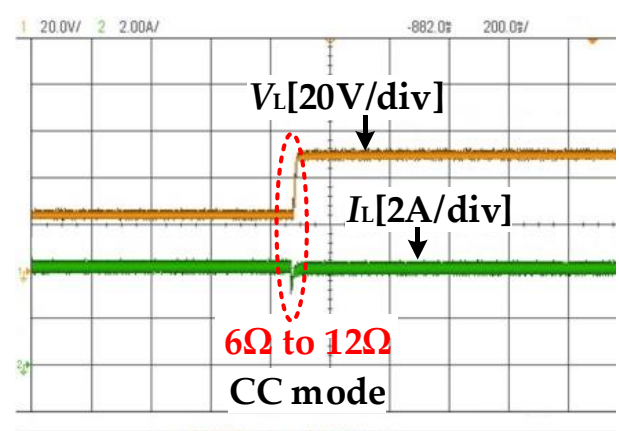

(a)

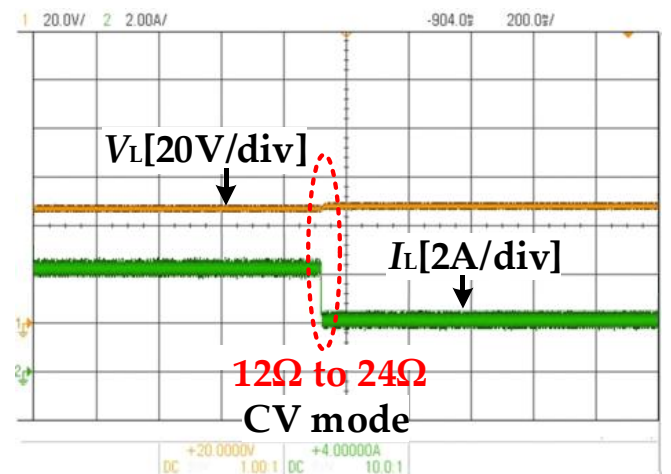

(b)

Figure 21. Dynamic performance of the proposed WPT system. (a) In CC mode, when the load changes from 6 to $12 \Omega ;(b)$ in CV mode, when the load changes from 12 to $24 \Omega$.

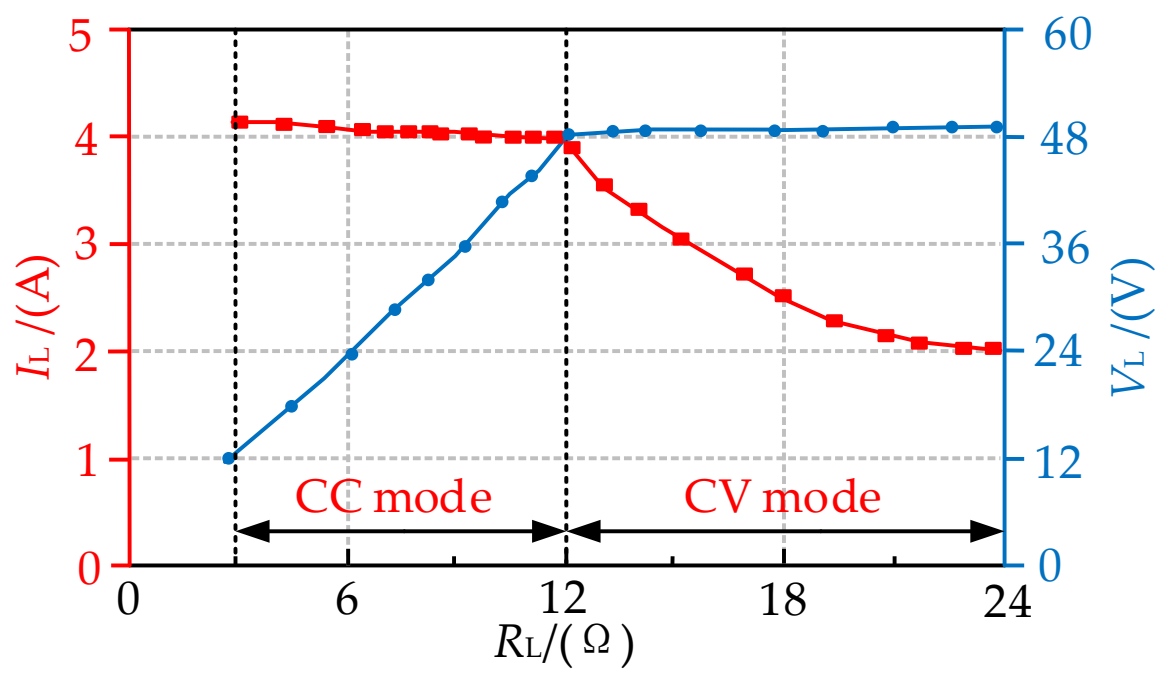

Figure 22. Measured output characteristics versus the load.

As shown in Table 3, the performance of the work in this paper is compared with other existing single-switch circuit based WPT. It can be seen that the proposed topology with the composite shielding structure can achieve higher efficiency. 


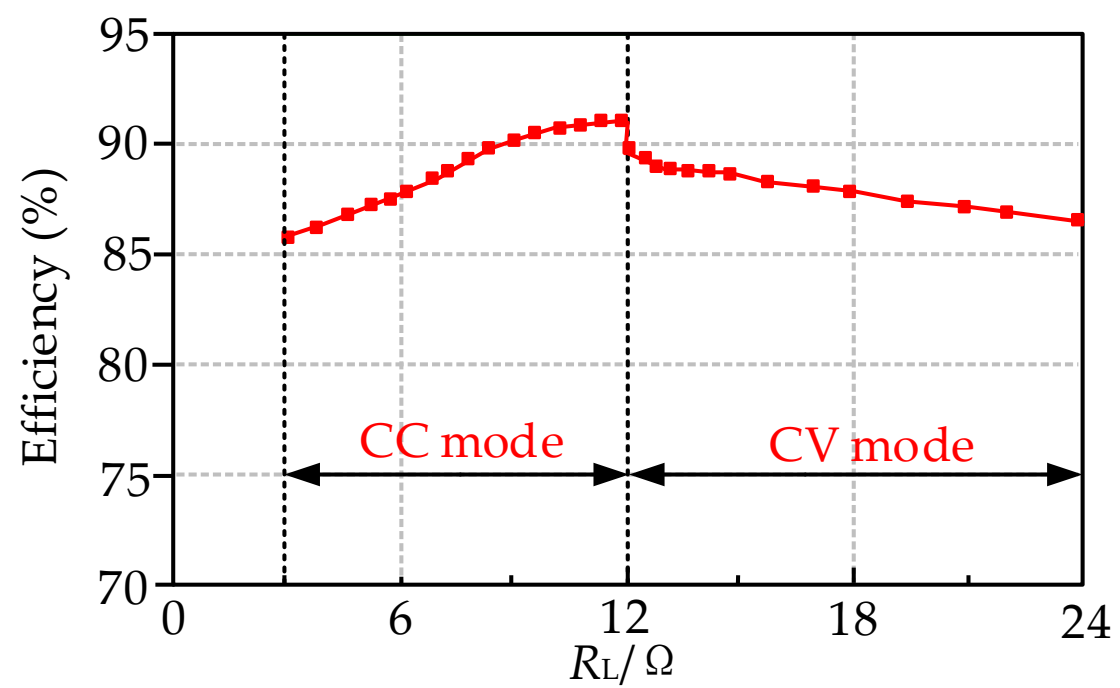

Figure 23. Diagram of efficiency versus the load.

Table 3. Performance comparison of single-switch.

\begin{tabular}{cccccc}
\hline Reference & Input Voltage & Output Power & CC/CV & $\begin{array}{c}\text { Coupling } \\
\text { Coefficient }\end{array}$ & $\begin{array}{c}\text { Maximum } \\
\text { Efficiency }\end{array}$ \\
\hline Proposed & $96 \mathrm{~V}$ & $192 \mathrm{~W}$ & $\mathrm{CC}$ and CV & 0.39 & $91.4 \%$ \\
{$[13]$} & $150 \mathrm{~V}$ & $60 \mathrm{~W}$ & $\mathrm{CC}$ and CV & $\mathrm{N} / \mathrm{A}$ & $78.2 \%$ \\
{$[14]$} & $5 \mathrm{~V}$ & $11 \mathrm{~W}$ & $\mathrm{CV}$ & 0.564 & $86.4 \%$ \\
{$[15]$} & $48 \mathrm{~V}$ & $350 \mathrm{~W}$ & $\mathrm{CV}$ & 0.30 & $87.1 \%$ \\
\hline
\end{tabular}

\section{Conclusions}

This paper presents a novel hybrid compensation topology of single-switch circuit to realize the constant-current and constant-voltage output. The properties of topology are verified by the experiments. Here, the output current is $4 \mathrm{~A}$ in constant-current mode, the output voltage is $48 \mathrm{~V}$ in constant-voltage mode, and the maximum efficiency is $91.4 \%$ in CC mode. It is simple to control the constant-current and constant-voltage output by changing the compensation network. In addition, soft-switching can be realized to reduce the switching loss. The proposed topology can be used as a battery charger, which has a good application value. The magnetic coupler adopts a composite shielding structure composed of ferrite, nanocrystalline strip, and aluminium foil. The advantages of the composite shielding structure in reducing the magnetic flux leakage are verified in simulation. Furthermore, the coupling effect between the coils is no less than the double-layer shielding structure.

Author Contributions: Methodology, Q.Z.; software, Z.G.; formal analysis, Q.Z.; investigation, L.Y.; writing-original draft preparation, Q.Z.; writing-review and editing, C.W.; visualization, L.Y.; funding acquisition, C.W. All authors have read and agreed to the published version of the manuscript.

Funding: This research was funded by the National Natural Science Foundation of China, grant number 51877113.

Institutional Review Board Statement: Not applicable.

Informed Consent Statement: Not applicable.

Conflicts of Interest: The authors declare no conflict of interest. 


\section{References}

1. Mekikis, P.-V.; Antonopoulos, A.; Kartsakli, E.; Lalos, A.S.; Alonso, L.; Verikoukis, C. Information Exchange in Randomly Deployed Dense WSNs With Wireless Energy Harvesting Capabilities. IEEE Trans. Wirel. Commun. 2016, 15, $3008-3018$. [CrossRef]

2. Ayestarán, R.G.; León, G.; Pino, M.R.; Nepa, P. Wireless power transfer through simultaneous near-field focusing and far-field synthesis. IEEE Trans. Antennas Propag. 2019, 67, 5623-5633. [CrossRef]

3. Dai, X.; Wu, J.; Jiang, J.; Gao, R.; Madawala, U.K. An Energy Injection Method to Improve Power Transfer Capability of Bidirectional WPT System with Multiple Pickups. IEEE Trans. Power Electron. 2021, 36, 5095-5107. [CrossRef]

4. Sun, Y.; Zhang, H.; Hu, A.P.; Tang, C.; Xiang, L. The Recognition and Control of Nonideal Soft-Switching Frequency for Wireless Power Transfer System Based on Waveform Identification. IEEE Trans. Power Electron. 2017, 32, 6617-6627. [CrossRef]

5. Barsari, V.Z.; Thrimawithana, D.J.; Covic, G.A. An Inductive Coupler Array for In-Motion Wireless Charging of Electric Vehicles. IEEE Trans. Power Electron. 2021, 36, 9854-9863. [CrossRef]

6. Song, B.; Cui, S.; Li, Y.; Zhu, C. A Fast and General Method to Calculate Mutual Inductance for EV Dynamic Wireless Charging System. IEEE Trans. Power Electron. 2021, 36, 2696-2709. [CrossRef]

7. Thai, V.X.; Jang, G.C.; Jeong, S.Y.; Park, J.H.; Kim, Y.S.; Rim, C.T. Symmetric Sensing Coil Design for the Blind-Zone Free Metal Object Detection of a Stationary Wireless Electric Vehicles Charger. IEEE Trans. Power Electron. 2020, 35, 3466-3477. [CrossRef]

8. Zhou, J.; Zhang, B.; Xiao, W.; Qiu, D.; Chen, Y. Nonlinear Parity Time Symmetric Model for Constant Efficiency Wireless Power Transfer: Application to a Drone-in-Flight Wireless Charging Platform. IEEE Trans. Ind. Electron. 2019, 66, 4097-4107. [CrossRef]

9. Arteaga, J.M.; Aldhaher, S.; Kkelis, G.; Kwan, C.; Yates, D.C.; Mitcheson, P.D. Dynamic Capabilities of Multi-MHz Inductive Power Transfer Systems Demonstrated with Batteryless Drones. IEEE Trans. Power Electron. 2019, 34, 5093-5104. [CrossRef]

10. Liu, C.; Jiang, C.; Song, J.; Cha, K.T. An Effective Sandwiched Wireless Power Transfer System for Charging Implantable Cardiac Pacemaker. IEEE Trans. Ind. Electron. 2019, 66, 4108-4117. [CrossRef]

11. Sedehi, R.; Budgett, D.; Jiang, J.; Ziyi, X.; Dai, X.; Hu, A.P.; McCormick, D. A Wireless Power Method for Deeply Implanted Biomedical Devices via Capacitively Coupled Conductive Power Transfer. IEEE Trans. Power Electron. 2021, 36, $1870-1882$. [CrossRef]

12. Hassan, N.U.; Hong, S.-W.; Lee, B. A Robust Multioutput Self-Regulated Rectifier for Wirelessly Powered Biomedical Applications. IEEE Trans. Ind. Electron. 2021, 68, 5466-5472. [CrossRef]

13. Lee, Y.-D.; Kim, K.-W.; Moon, G.-W. A Self-Compensated Planar Coil with Integrated Single-Switch Regulator for Wireless Power Transfer (WPT) Systems. IEEE Trans. Power Electron. 2021, 36, 10954-10958. [CrossRef]

14. Huang, Y.; Lee, A.T.-L.; Tan, S.-C.; Hui, S.Y. Highly Efficient Wireless Power Transfer System with Single-Switch Step-Up Resonant Inverter. IEEE J. Emerg. Sel. Topics Power Electron. 2021, 9, 1157-1168. [CrossRef]

15. Huang, X.; Kong, Y.; Ouyang, Z.; Chen, W.; Lin, S. Analysis and Comparison of Push-Pull Class-E Inverters with Magnetic Integration for Megahertz Wireless Power Transfer. IEEE Trans. Power Electron. 2020, 35, 565-577. [CrossRef]

16. Tebianian, H.; Salami, Y.; Jeyasurya, B.; Quaicoe, J.E. A 13.56-MHz Full-Bridge Class-D ZVS Inverter with Dynamic Dead-Time Control for Wireless Power Transfer Systems. IEEE Trans. Ind. Electron. 2020, 67, 1487-1497. [CrossRef]

17. Li, H.; Wang, K.; Fang, J.; Tang, Y. Pulse Density Modulated ZVS Full-Bridge Converters for Wireless Power Transfer Systems. IEEE Trans. Power Electron. 2019, 34, 369-377. [CrossRef]

18. Samanta, S.; Rathore, A.K.; Thrimawithana, D.J. Bidirectional Current-Fed Half-Bridge (C) (LC)-(LC) Configuration for Inductive Wireless Power Transfer System. IEEE Trans. Ind. Appl. 2017, 53, 4053-4062. [CrossRef]

19. Trung, N.K.; Ogata, T.; Tanaka, S.; Akatsu, K. Attenuate Influence of Parasitic Elements in 13.56-MHz Inverter for Wireless Power Transfer Systems. IEEE Trans. Power Electron. 2018, 33, 3218-3231. [CrossRef]

20. Vu, V.; Tran, D.; Choi, W. Implementation of the Constant Current and Constant Voltage Charge of Inductive Power Transfer Systems with the Double-Sided LCC Compensation Topology for Electric Vehicle Battery Charge Applications. IEEE Trans. Power Electron. 2018, 33, 7398-7410. [CrossRef]

21. Chen, Y.; Li, M.; Yang, B.; Chen, S.; Li, Q.; He, Z.; Mai, R. Variable-Parameter T-Circuit-Based IPT System Charging Battery with Constant Current or Constant Voltage Output. IEEE Trans. Power Electron. 2020, 35, 1672-1684. [CrossRef]

22. Ahn, D.; Kim, S.; Moon, J.; Cho, I. Wireless Power Transfer with Automatic Feedback Control of Load Resistance Transformation. IEEE Trans. Power Electron. 2016, 31, 7876-7886. [CrossRef]

23. Buja, G.; Bertoluzzo, M.; Mude, K.N. Design and Experimentation of WPT Charger for Electric City Car. IEEE Trans. Ind. Electron. 2015, 62, 7436-7447. [CrossRef]

24. Qu, X.; Chu, H.; Wong, S.; Tse, C.K. An IPT Battery Charger with Near Unity Power Factor and Load-Independent Constant Output Combating Design Constraints of Input Voltage and Transformer Parameters. IEEE Trans. Power Electron. 2019, 34, 7719-7727. [CrossRef]

25. Yue, R.; Wang, C.; Li, H.; Liu, Y. Constant-Voltage and Constant-Current Output Using P-CLCL Compensation Circuit for Single-Switch Inductive Power Transfer. IEEE Trans. Power Electron. 2021, 36, 5181-5190. [CrossRef]

26. Wang, D.; Qu, X.; Yao, Y.; Yang, P. Hybrid Inductive-Power-Transfer Battery Chargers for Electric Vehicle Onboard Charging with Configurable Charging Profile. IEEE Trans. Intell. Transp. Syst. 2021, 22, 592-599. [CrossRef] 
27. Chen, Y.; Zhang, H.; Park, S.; Kim, D. A Switching Hybrid LCC-S Compensation Topology for Constant Current/Voltage EV Wireless Charging. IEEE Access 2019, 7, 133924-133935. [CrossRef]

28. Li, Y.; Hu, J.; Liu, M.; Chen, Y.; Chan, K.W.; He, Z.; Mai, R. Reconfigurable Intermediate Resonant Circuit Based WPT System with Load-Independent Constant Output Current and Voltage for Charging Battery. IEEE Trans. Power Electron. 2019, 34, $1988-1992$. [CrossRef] 